\title{
Support for Seasonal Influenza Vaccination Requirements among US Healthcare Personnel
}

\author{
Jürgen Maurer, $\mathrm{PhD} ;{ }^{1,2}$ Katherine M. Harris, $\mathrm{PhD} ;{ }^{1}$ Carla L. Black, $\mathrm{PhD} ;^{3}$ Gary L. Euler, $\mathrm{DrPH}^{3}$
}

(See the commentary by Russi and Baltimore, on pages 222-223.)

овjестіve. To measure support for seasonal influenza vaccination requirements among US healthcare personnel (HCP) and its associations with attitudes regarding influenza and influenza vaccination and self-reported coverage by existing vaccination requirements.

DEsign. Between June 1 and June 30,2010 , we surveyed a sample of US HCP $(n=1,664)$ recruited using an existing probability-based online research panel of participants representing the US general population as a sampling frame.

SETTING. General community.

PARTICIPANTs. Eligible HCP who (1) reported having worked as medical doctors, health technologists, healthcare support staff, or other health practitioners or who (2) reported having worked in hospitals, ambulatory care facilities, long-term care facilities, or other healthrelated settings.

мвтнорs. We analyzed support for seasonal influenza vaccination requirements for $\mathrm{HCP}$ using proportion estimation and multivariable probit models.

RESULTS. A total of 57.4\% (95\% confidence interval, 53.3\%-61.5\%) of US HCP agreed that HCP should be required to be vaccinated for seasonal influenza. Support for mandatory vaccination was statistically significantly higher among HCP who were subject to employerbased influenza vaccination requirements, who considered influenza to be a serious disease, and who agreed that influenza vaccine was safe and effective.

ConCLUsions. A majority of HCP support influenza vaccination requirements. Moreover, providing HCP with information about the safety of influenza vaccination and communicating that immunization of HCP is a patient safety issue may be important for generating staff support for influenza vaccination requirements.

Infect Control Hosp Epidemiol 2012;33(3):213-221

Influenza causes significant morbidity and mortality each year. ${ }^{1-4}$ Influenza is especially serious in persons with weakened immune systems or certain chronic conditions, pregnant women, young children, and older adults, as reflected in the large concentration of influenza-related hospitalizations and mortality within those groups. ${ }^{1-4}$ Annual influenza vaccination is the primary method of preventing influenza disease and virus transmission. ${ }^{4}$ Because the efficacy and effectiveness of influenza vaccination vary by age and immunocompetence, ${ }^{4}$ vaccinating close physical contacts of vulnerable individuals may protect them from influenza-related complications and death..$^{4-7}$ Vaccinating healthcare personnel (HCP) can reduce the risk of transmission of influenza virus to vulnerable patients in healthcare settings and can reduce influenza-related absenteeism of HCP during influenza outbreaks. ${ }^{8,9}$ For this reason, the Advisory Committee on Im- munization Practices recommends influenza vaccination of all $\mathrm{HCP}$ to protect themselves, their household contacts, and vulnerable patients with whom they may be in contact. ${ }^{4}$ However, recent data indicate that many HCP neglect to be vaccinated for influenza, even during a public health emergency, such as the 2009-2010 influenza $\mathrm{A}(\mathrm{H} 1 \mathrm{~N} 1)$ pandemic. ${ }^{10}$

Concern about the low levels of vaccination among HCP has led a variety of professional organizations, such as the American Academy of Pediatrics, the Infectious Diseases Society of America, the National Patient Safety Foundation, the Society for Healthcare Epidemiology of America, and the Association for Professionals in Infection Control and Epidemiology, to stress influenza vaccination requirements for $\mathrm{HCP}$, and an increasing number of institutions require their staff to be vaccinated..$^{11-17}$ In practice, these requirements take a variety of forms, ranging from permissive guidance that

Affiliations: 1. RAND Corporation, Arlington, Virginia; 2. Institute of Health Economics and Management, University of Lausanne, Switzerland; 3. Centers for Disease Control and Prevention, Atlanta, Georgia.

Received September 19, 2011 ; accepted October 24, 2011; electronically published January 19, 2012.

(C) 2012 by The Society for Healthcare Epidemiology of America. All rights reserved. 0899-823X/2012/3303-0001\$15.00. DOI: 10.1086/664056 
TABLE 1. Characteristics of an Analytical Sample representing US Healthcare Personnel (HCP), June 2010

\begin{tabular}{|c|c|c|}
\hline \multirow[b]{2}{*}{ Characteristic } & \multicolumn{2}{|c|}{ Prevalence of characteristic } \\
\hline & $\begin{array}{l}\text { Unweighted, no. of HCP } \\
\qquad(n=1,664)\end{array}$ & Weighted, ${ }^{a} \%(95 \% \mathrm{CI})$ \\
\hline \multicolumn{3}{|l|}{ Setting } \\
\hline Hospital & 694 & $36.5(32.5-40.5)$ \\
\hline Ambulatory, outpatient, or medical clinic & 434 & $23.6(20.3-26.9)$ \\
\hline Long-term care & 320 & $25.6(21.7-29.6)$ \\
\hline Other ${ }^{b}$ & 216 & $14.3(11.2-17.3)$ \\
\hline \multicolumn{3}{|l|}{ Occupation } \\
\hline Medical doctor, physician assistant, nurse practitioner, or dentist & 113 & $5.7(4.1-7.3)$ \\
\hline Nurse & 447 & $21.0(17.7-24.2)$ \\
\hline Allied health professional & 571 & $34.9(31.0-38.8)$ \\
\hline Administration and management & 288 & $16.2(13.2-19.2)$ \\
\hline Other ${ }^{\varepsilon}$ & 245 & $22.2(18.2-26.1)$ \\
\hline \multicolumn{3}{|l|}{ Patient contact } \\
\hline \multicolumn{3}{|l|}{ Involved in hands-on patient care } \\
\hline Yes & 1,100 & $65.5(61.5-69.6)$ \\
\hline No & 564 & $34.5(30.4-38.5)$ \\
\hline \multicolumn{3}{|l|}{ Works around seriously ill patients } \\
\hline Yes & 487 & $26.1(22.6-29.6)$ \\
\hline No & 1,177 & $73.9(70.4-77.4)$ \\
\hline \multicolumn{3}{|l|}{ Has regular contact with patients with influenza } \\
\hline Yes & 866 & $52.1(47.9-56.2)$ \\
\hline No & 798 & $47.9(43.8-52.1)$ \\
\hline \multicolumn{3}{|l|}{ Employer vaccination policy } \\
\hline None & 342 & $26.3(22.2-30.3)$ \\
\hline Recommended & 1,136 & $62.6(58.3-66.8)$ \\
\hline \multicolumn{3}{|l|}{ Required } \\
\hline Without penalty & 75 & $5.0(3.1-7.0)$ \\
\hline With penalty & 111 & $6.1(4.2-8.0)$ \\
\hline \multicolumn{3}{|l|}{ Vaccination status: vaccinated for seasonal influenza } \\
\hline Yes & 1,095 & $61.8(57.7-65.9)$ \\
\hline No & 569 & $38.2(34.1-42.3)$ \\
\hline \multicolumn{3}{|l|}{ Attitudes and beliefs } \\
\hline \multicolumn{3}{|l|}{ I am at risk of getting seasonal flu } \\
\hline Agreement & 1,382 & $81.2(77.8-84.6)$ \\
\hline Disagreement & 282 & $18.8(15.4-22.2)$ \\
\hline \multicolumn{3}{|l|}{ People around me are at risk of getting seasonal flu } \\
\hline Agreement & 1,487 & $86.3(83.0-89.6)$ \\
\hline Disagreement & 177 & $13.7(10.4-17.0)$ \\
\hline \multicolumn{3}{|l|}{ Seasonal flu is a serious threat to my health } \\
\hline Agreement & 953 & $57.5(53.4-61.6)$ \\
\hline Disagreement & 711 & $42.5(38.4-46.6)$ \\
\hline \multicolumn{3}{|l|}{ Seasonal flu is a serious threat to the health of people around me } \\
\hline Agreement & 1,248 & $73.3(69.5-77.2)$ \\
\hline Disagreement & 416 & $26.7(22.8-30.5)$ \\
\hline \multicolumn{3}{|l|}{ Seasonal flu vaccination can protect me from seasonal flu } \\
\hline Agreement & 1,329 & $76.4(72.6-80.2)$ \\
\hline Disagreement & 335 & $23.6(19.8-27.4)$ \\
\hline \multicolumn{3}{|l|}{$\begin{array}{l}\text { If I get a seasonal flu vaccination, people around me will be bet- } \\
\text { ter protected from seasonal flu }\end{array}$} \\
\hline Agreement & 1,153 & $66.0(61.9-70.1)$ \\
\hline Disagreement & 511 & $34.0(29.9-38.1)$ \\
\hline \multicolumn{3}{|l|}{ Seasonal flu vaccination is safe } \\
\hline Agreement & 1,398 & $80.5(76.9-84.1)$ \\
\hline Disagreement & 266 & $19.5(15.9-23.1)$ \\
\hline
\end{tabular}




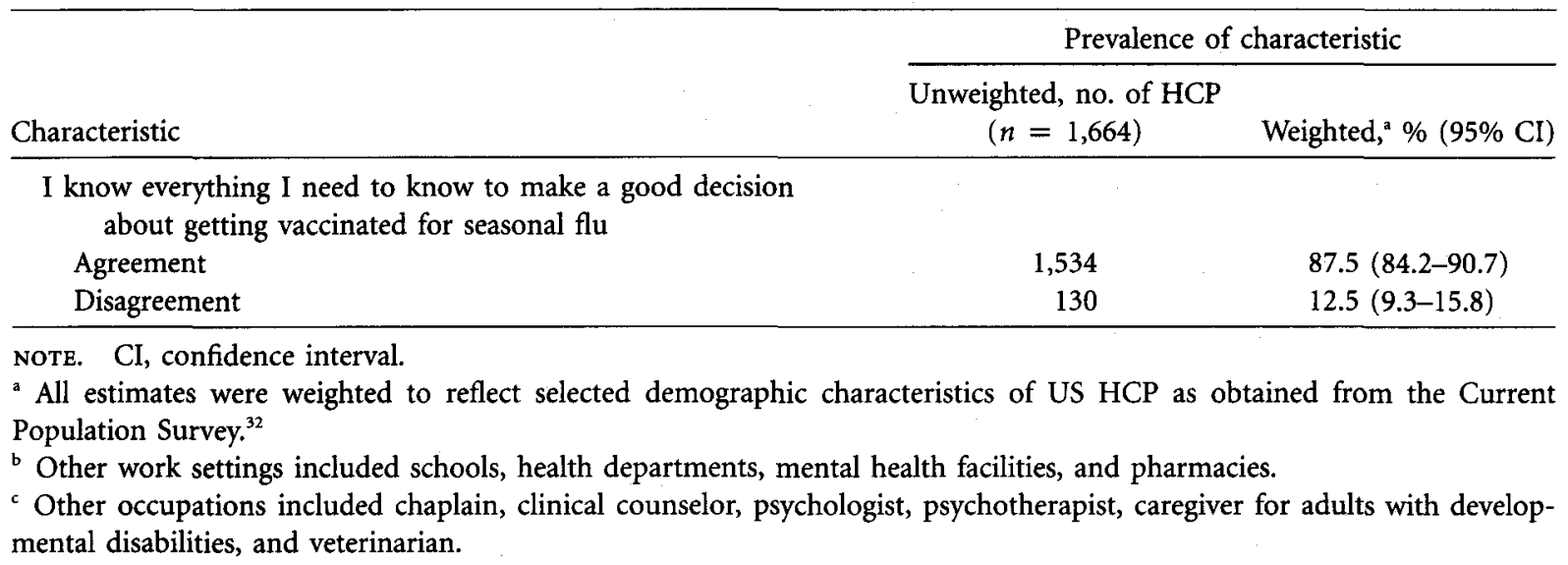

allows for opting out of vaccination (eg, via a declination statement) to strict mandates that require vaccination as a condition of employment with very limited exceptions. ${ }^{17}$ Both nationally representative data and in-depth case reports suggest that vaccination requirements are effective in increasing vaccine uptake among $\mathrm{HCP} .{ }^{10,18,19}$ However, mandatory influenza vaccination for HCP can be controversial, as evidenced by several lawsuits filed by unions representing workers against hospitals and other institutions that have instituted vaccination requirements. ${ }^{20-28}$

Although vaccination requirements are the source of much public debate, little is known about the level and correlates of support for requirements among HCP who are directly affected by these policies. To fill this gap, we report data from a recently conducted online panel survey of US HCP and describe the level of support for HCP influenza vaccination requirements overall and by work setting, occupation, patient contact, current employer policies with regard to influenza and influenza vaccination, and attitudes concerning influenza and influenza vaccination.

\section{METHODS}

This study analyzes self-reported data from the last survey wave of a series of 7 monthly longitudinal tracking surveys, which were designed to monitor influenza vaccination coverage among HCP during the 2009 influenza $\mathrm{A}(\mathrm{H} 1 \mathrm{~N} 1)$ pandemic. The data presented here were collected between June 1 and June 30, 2010, and comprise a sample of self-identified HCP drawn from a nationally representative, online panel operated by Knowledge Networks (KN; Menlo Park, California). The $\mathrm{KN}$ panel contains approximately 40,000 US households that were randomly selected using both randomdigit dial telephone and address-based probability sampling. This dual sampling frame covers both non-Internet and cellular phone-only households. Adults in selected households were invited by telephone or mail to participate in the panel. Surveys were completed online. $\mathrm{KN}$ provided offline households with Internet access and required hardware in return for participating in the panel. Others par- ticipated using their own computers and Internet connections and received a small financial remuneration for participating. Additional information about the KN panel can be obtained at http://www.knowledgenetworks.com/ ganp/docs/Knowledge\%20Networks\%20Methodology.pdf. Data from KN surveys have been published in a wide variety of peer-reviewed medical and social science journals. ${ }^{29}$

Initial eligibility for the HCP survey was based on responses to a profile questionnaire that was administered upon recruitment into the $\mathrm{KN}$ panel and regularly updated by $\mathrm{KN}$. The profile questionnaire asks panelists to describe their occupational characteristics and work setting on the basis of the Standard Occupational Classification system and the North American Industry Classification System. Specifically, panelists were asked to complete our survey if they indicated (1) work as a medical doctor (eg, physician, surgeon, dentist, or veterinarian), health technologist or technician (eg, paramedic or laboratory technician), or healthcare support staff (eg, nursing aide, orderly, or dental assistant) or if they reported (2) work in a hospital, ambulatory care facility, nursing facility, residential care facility, or other health-related setting. This initial screening procedure, based on $\mathrm{KN}$ profile data, identified 2,735 panelists that were eligible for our survey.

A total of 2,001 (73.2\%) of eligible $\mathrm{KN}$ panelists responded to the June survey. To increase the specificity of our analytic sample, we fielded detailed questions about work arrangements and the nature of patient contact during the previous 12 months as part of our survey. Consistent with definitions of HCP from other national data sources, ${ }^{30,31}$ we considered only respondents who either work in a healthcare-related setting or were otherwise involved in hands-on care of patients (1,798 respondents). After excluding an additional 134 respondents with missing information for any item used in this analysis, our final analytical sample comprised 1,664 respondents.

Support of mandatory influenza vaccination and other attitudes and beliefs regarding influenza and influenza vaccination were measured by the indicated level of agreement with a series of statements whose exact wording is presented 
TA B LE 2. Unadjusted Associations between Support of Seasonal Influenza Vaccination Requirements among US Healthcare Personnel (HCP) and Their Occupational Characteristics and Influenza Vaccination-Related Attitudes and Beliefs, June 2010

\begin{tabular}{|c|c|c|c|}
\hline \multirow[b]{2}{*}{ Characteristic } & \multicolumn{3}{|c|}{$\begin{array}{l}\text { Agreement with statement "healthcare workers should be } \\
\text { required to be vaccinated for seasonal flu" }\end{array}$} \\
\hline & $\begin{array}{l}\text { Unweighted, no. of HCP } \\
\text { in agreement/total } \\
(n=1,664)\end{array}$ & Weighted, $\%$ (95\% CI) & $P$ \\
\hline All HCP & $918 / 1,664$ & $57.4(53.3-61.5)$ & \\
\hline Setting & & & .014 \\
\hline Hospital & $381 / 694$ & $52.5(45.8-59.2)$ & \\
\hline Ambulatory, outpatient, or medical clinic & $225 / 434$ & $57.2(49.9-64.5)$ & \\
\hline Long-term care & $178 / 320$ & $55.9(46.7-65.2)$ & \\
\hline Other $^{\mathrm{b}}$ & $134 / 216$ & $73.1(64.4-81.7)$ & \\
\hline Occupation & & & .427 \\
\hline Medical doctor, physician assistant, nurse practitioner, or dentist & $64 / 113$ & $65.3(52.7-77.9)$ & \\
\hline Nurse & $211 / 447$ & $51.1(42.6-59.7)$ & \\
\hline Allied health professional & $312 / 571$ & $56.5(49.9-63.2)$ & \\
\hline Administration and management & $174 / 288$ & $60.5(50.7-70.2)$ & \\
\hline Other $^{c}$ & $157 / 245$ & $60.5(50.0-71.0)$ & \\
\hline \multicolumn{4}{|l|}{ Patient contact } \\
\hline Involved in hands-on patient care & & & .789 \\
\hline Yes & $581 / 1,100$ & $57.8(52.9-62.8)$ & \\
\hline No & $337 / 564$ & $56.6(49.3-64.0)$ & \\
\hline Works around seriously ill patients & & & .975 \\
\hline Yes & $261 / 487$ & $57.5(50.0-65.0)$ & \\
\hline No & $657 / 1,177$ & $57.4(52.5-62.3)$ & \\
\hline Has regular contact with influenza patients & & & .015 \\
\hline Yes & $501 / 866$ & $62.3(56.8-67.8)$ & \\
\hline No & $417 / 798$ & $52.1(46.1-58.2)$ & \\
\hline Employer vaccination policy & & & $<.001$ \\
\hline None & $161 / 342$ & $52.6(43.3-62.0)$ & \\
\hline Recommended & $600 / 1,136$ & $54.6(49.7-59.4)$ & \\
\hline \multicolumn{4}{|l|}{ Required } \\
\hline Without penalty & $68 / 75$ & $94.7(90.0-99.3)$ & \\
\hline With penalty & $89 / 111$ & $76.6(61.1-92.2)$ & \\
\hline Vaccinated for seasonal influenza & & & $<.001$ \\
\hline Yes & $757 / 1,095$ & $71.5(66.8-76.2)$ & \\
\hline No & $161 / 569$ & $28.5(23.8-33.2)$ & \\
\hline \multicolumn{4}{|l|}{ Attitudes and beliefs } \\
\hline I am at risk of getting seasonal flu & & & $<.001$ \\
\hline Agreement & $829 / 1,382$ & $61.4(56.9-65.8)$ & \\
\hline Disagreement & $89 / 282$ & $40.4(30.3-50.5)$ & \\
\hline People around me are at risk of getting seasonal flu & & & .040 \\
\hline Agreement & $863 / 1,487$ & $59.4(55.1-63.7)$ & \\
\hline Disagreement & $55 / 177$ & $45.0(31.9-58.1)$ & \\
\hline Seasonal flu is a serious threat to my health & & & $<.001$ \\
\hline Agreement & $652 / 953$ & $71.2(66.2-76.1)$ & \\
\hline Disagreement & $266 / 711$ & $38.8(32.6-45.0)$ & \\
\hline Seasonal flu is a serious threat to the health of people around me & & & $<.001$ \\
\hline Agreement & $788 / 1,248$ & $66.8(62.4-71.2)$ & \\
\hline Disagreement & $130 / 416$ & $31.6(23.6-39.6)$ & \\
\hline Seasonal flu vaccination can protect me from seasonal flu & & & $<.001$ \\
\hline Agreement & $867 / 1,329$ & $68.4(64.2-72.7)$ & \\
\hline Disagreement & $51 / 335$ & $21.8(13.1-30.5)$ & \\
\hline $\begin{array}{l}\text { If I get a seasonal flu vaccination, people around me will be } \\
\text { better protected from seasonal flu }\end{array}$ & & & $<.001$ \\
\hline Agreement & $768 / 1,153$ & $70.1(65.6-74.5)$ & \\
\hline Disagreement & $150 / 511$ & $32.8(25.6-40.0)$ & \\
\hline
\end{tabular}




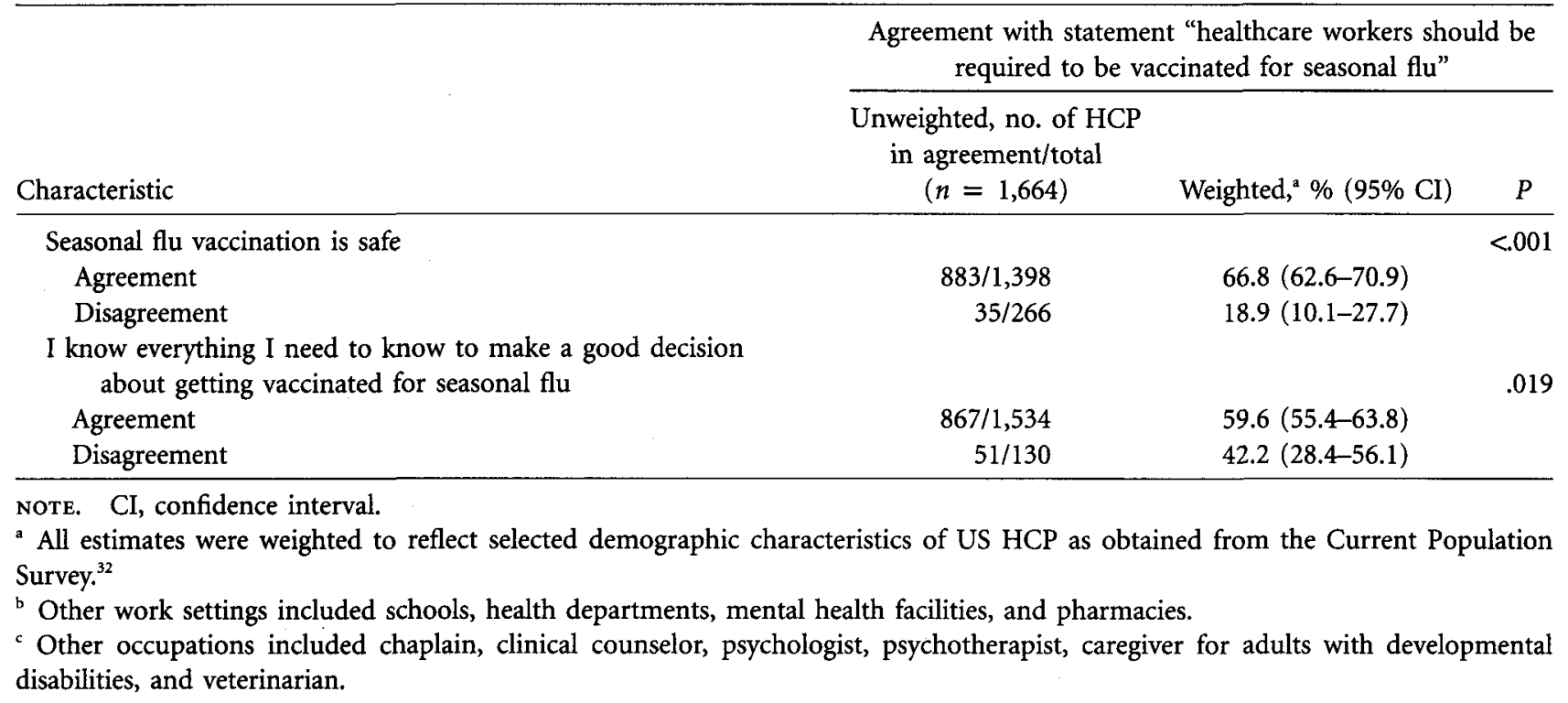

in the results tables (Tables 1-3). For each of these statements, the respondents indicated their level of agreement on a 4point scale ranging from "strongly agree" to "strongly disagree." We categorized the response categories "strongly agree" and "agree" as "agreement" and the response categories "disagree" and "strongly disagree" as "disagreement."

We report unadjusted and adjusted associations between support of mandatory influenza vaccination and work setting, occupation, involvement in patient care, workplace vaccination requirements, and attitudes and beliefs described in the tables. The nature of patient contact was measured by (1) involvement in hands-on patient care, (2) work around seriously ill patients, and (3) regular contact with patients with influenza and patients with influenza-like symptoms during the previous 12 months. Being covered by an employer-based vaccination requirement for seasonal influenza was assessed by asking respondents. whether their employer recommended or required influenza vaccination for seasonal influenza during the previous 12 months. If a respondent indicated being subject to a vaccination requirement, the survey followed up with an additional question regarding whether there were "any penalties for personnel that did not comply with this requirement." If the respondent indicated that there were penalties, a check-off list of potential penalties was provided.

Statistical analyses were conducted using survey data analysis commands in Stata, version 10.1 (Stata). Sample characteristics and unadjusted associations were computed using proportion estimation commands. The adjusted associations were computed on the basis of a probit model. Adjusted associations are reported in terms of average partial effects (ie, the average percentage point change in the probability of support of mandatory vaccination associated with a 1-unit change in the value of the variable of interest controlling for other characteristics). Adjusted Wald tests were used to assess the statistical significance of group differences. All estimates were weighted to reflect selected demographic and geographic characteristics (age, sex, race/ethnicity, education, census region, metropolitan vs nonmetropolitan area, and home Internet access status) of the US population of HCP, as reflected in the most recent monthly Current Population Survey, ${ }^{32}$ and occupational characteristics (medical doctor, other healthcare practitioner, health technologist or technician, healthcare support, and other occupation) and work settings (ambulatory care, hospital, long-term care, and other work setting) as measured in the KN profile questionnaire. The RAND Corporation's institutional reviewed board approved the study design and surveys.

\section{RES ULT S}

The final analytical sample of HCP was distributed across a wide variety of work arrangements, reflecting the diversity of HCP employed in the United States (Table 1). A total of $62.6 \%$ of HCP were recommended for seasonal vaccination by their employers, whereas another $11.1 \%$ reported that their employer required them to be vaccinated for seasonal influenza. Slightly more than half of those required to be vaccinated reported a penalty for noncompliance (Table 1).

A total of $61.8 \%$ of $\mathrm{HCP}$ were vaccinated for seasonal influenza, and $81.2 \%$ and $86.3 \%$ of HCP considered themselves or people around them to be at risk for influenza, respectively. However, although only $57.5 \%$ perceived seasonal influenza to be a serious threat to their health, $73.3 \%$ considered seasonal influenza to be a serious threat to the health of others around them. A total of $76.4 \%$ of HCP regarded vaccination to be effective in protecting themselves from seasonal influenza, but slightly fewer HCP (66.0\%) be- 
lieved that being vaccinated themselves offered protection to the people around them. Additionally, $80.5 \%$ of HCP thought that seasonal influenza vaccination was safe, and $87.5 \%$ reported that they had sufficient knowledge to make a good decision about whether to be vaccinated against seasonal influenza.

Overall, a majority (57.4\%) of US HCP agreed that HCP should be required to be vaccinated for seasonal influenza (Table 2). Just over half of HCP working in hospitals or in outpatient or long-term care settings indicated their support of vaccination requirements for seasonal influenza, whereas support was considerably more common in other settings, such as school clinics, occupational health clinics, and health departments. Medical doctors, physicians' assistants, nurse practitioners, and dentists indicated the highest level of support for seasonal influenza vaccination requirements $(65.3 \%)$ and support was lowest among nurses $(51.1 \%)$, although the overall differences in level of support across occupation groups were not statistically significant. Although support for vaccination requirements for seasonal influenza was significantly higher among HCP who reported regular contact with influenza patients, compared with those without regular contact $(62.3 \%$ vs $52.1 \%)$, support did not vary by HCP involvement in hands-on patient care or by whether $\mathrm{HCP}$ worked around seriously ill patients.

Support for vaccination requirements for seasonal influenza varied strongly by HCP current employer policy with regard to vaccination requirements, with the highest support of vaccination requirements among $\mathrm{HCP}$ covered by existing mandates (Table 2). Mandatory seasonal influenza vaccination for HCP was supported by $76.6 \%$ and $94.7 \%$ of $\mathrm{HCP}$ covered by vaccination requirements with and without identified penalties for noncompliance, respectively. Although support for seasonal vaccination requirements was lower among HCP whose employers had no vaccination policy or just recommended seasonal vaccination of those $\mathrm{HCP}, 52.6 \%$ and $54.6 \%$, respectively, also supported vaccination requirements.

Vaccine uptake and attitudes regarding seasonal influenza and seasonal influenza vaccination displayed statistically significant associations with support for seasonal vaccination requirements for HCP (Table 2). Support for such requirements was statistically significantly higher among HCP who were vaccinated, those who perceived themselves or their personal contacts to be at risk for getting seasonal influenza, those who considered seasonal influenza to be a serious threat for their own health or the health of people around them, and those who considered seasonal influenza vaccination to be effective in protecting them or their contacts from seasonal influenza. Support of vaccination requirements was statistically significantly higher among HCP who considered themselves to be sufficiently informed to make a good decision about whether to be vaccinated for seasonal influenza. Support of vaccination requirements was especially low among
$\mathrm{HCP}$ who did not think that seasonal influenza vaccination was safe $(18.9 \%)$.

Estimates from a multivariable probit model showed a significant adjusted association between support for seasonal influenza requirements and work setting, with HCP from settings outside the classical medical care domain showing higher levels of support for vaccination requirements (Table 3 ). By contrast, the adjusted associations between support for vaccination requirements and both occupation and involvement in hands-on patient care were not statistically significant. Working with seriously ill patients was associated with a $7.3 \%$ reduction in support for seasonal vaccination requirements. Having regular contact with influenza patients was associated with a $9.4 \%$ increase in support of vaccination mandates.

Being covered by employer vaccination policies remained strongly associated with support of seasonal vaccination mandates when controlling for work setting, occupation, patient contact, and seasonal influenza and vaccination-related attitudes. Being recommended for vaccination was not significantly associated with support for vaccination requirements. Yet, support for mandatory vaccination was $16.4 \%$ and $30.6 \%$ higher among HCP who were subject to an employer vaccination requirement with and without reported penalties for noncompliance, respectively.

Strong associations of seasonal influenza and seasonal influenza vaccination-related attitudes with seasonal influenza vaccination were found. Specifically, HCP who perceived seasonal influenza as a serious threat to their own health or to the health of people around them reported $11.6 \%$ and $12.4 \%$ higher rates of support for mandatory seasonal vaccination, respectively, compared with $\mathrm{HCP}$ who disagreed with these statements. Moreover, the perceived effectiveness of $\mathrm{HCP}$ vaccination in protecting $\mathrm{HCP}$ or people around them was associated with increases in the level of support for vaccination requirements of $14.3 \%$ and $9.3 \%$, respectively. Controlling for other factors, perceived vaccination safety was associated with a $17.0 \%$ higher level of support for seasonal vaccination requirements, whereas self-assessed vaccinationrelated knowledge was not statistically significant in the probit model.

\section{DISCUSSION}

Our survey showed that a slight majority of HCP support vaccination requirements for seasonal influenza. Our estimates of staff support of vaccination requirements for $\mathrm{HCP}$ are somewhat lower than those found in a previous study conducted at one institution that found that $70 \%$ of staff supported mandatory influenza vaccination of HCP from a random sample of physicians, nurses, and other hospital employees of Children's Mercy Hospital in Kansas City, Missouri. ${ }^{33}$ Support for vaccination requirements in our study was significantly higher among HCP who were currently covered by such requirements and was even higher when these 
TABLE 3. Adjusted Associations between Support of Seasonal Influenza Vaccination Requirements among US Healthcare Personnel (HCP) and Their Occupational Characteristics and Influenza Vaccination-Related Attitudes and Beliefs, June $2010(n=1,664)$

\begin{tabular}{|c|c|c|}
\hline \multirow[b]{2}{*}{ Variable } & \multicolumn{2}{|c|}{$\begin{array}{l}\text { Healthcare workers should be required } \\
\text { to be vaccinated for seasonal flu }\end{array}$} \\
\hline & Average partial effect ${ }^{2}(95 \% \mathrm{CI})$ & $P$ \\
\hline \multicolumn{3}{|l|}{ Setting } \\
\hline Hospital & Reference category & \\
\hline Ambulatory, outpatient, or medical clinic & $1.4(-7.2$ to 10.1$)$ & .743 \\
\hline Long-term care & $1.9(-7.0$ to 10.8$)$ & .674 \\
\hline Other ${ }^{b}$ & $15.1(5.6$ to 24.5$)$ & .002 \\
\hline \multicolumn{3}{|l|}{ Occupation } \\
\hline Medical doctor, physician assistant, nurse practitioner, or dentist & Reference category & \\
\hline Nurse & $-6.3(-17.7$ to 5.0$)$ & .275 \\
\hline Allied health professional & $-2.5(-12.8$ to 7.9$)$ & .642 \\
\hline Administration and management & $5.0(-8.3$ to 18.3$)$ & .460 \\
\hline Other ${ }^{\mathrm{c}}$ & $7.2(-5.0$ to 19.3$)$ & .247 \\
\hline \multicolumn{3}{|l|}{ Patient contact } \\
\hline \multicolumn{3}{|l|}{ Involved in hands-on patient care } \\
\hline Yes & $2.4(-5.8$ to 10.7$)$ & .560 \\
\hline \multicolumn{3}{|l|}{ Works around seriously ill patients } \\
\hline Yes & $-7.3(-15.3$ to 0.6$)$ & .069 \\
\hline \multicolumn{3}{|l|}{ Has regular contact with influenza patients } \\
\hline Yes & $9.4(2.9-15.9)$ & .004 \\
\hline \multicolumn{3}{|l|}{ Employer vaccination policy } \\
\hline None & Reference category & \\
\hline Recommended & $-4.2(-13.9$ to 5.6$)$ & .402 \\
\hline \multicolumn{3}{|l|}{ Required } \\
\hline Without penalty & $30.6(21.1-40.2)$ & $<.001$ \\
\hline With penalty & $16.4(-1.1$ to 33.8$)$ & .066 \\
\hline \multicolumn{3}{|l|}{ Attitudes and beliefs } \\
\hline \multicolumn{3}{|l|}{ I am at risk of getting seasonal flu } \\
\hline Agreement & $-6.7(-17.8$ to 4.4$)$ & .236 \\
\hline \multicolumn{3}{|l|}{ People around me are at risk of getting seasonal flu } \\
\hline Agreement & $-9.9(-22.3$ to 2.4$)$ & .115 \\
\hline \multicolumn{3}{|l|}{ Seasonal flu is a serious threat to my health } \\
\hline Agreement & $11.6(3.6-19.5)$ & .005 \\
\hline \multicolumn{3}{|l|}{ Seasonal flu is a serious threat to the health of people around me } \\
\hline Agreement & $12.4(3.0-21.7)$ & .010 \\
\hline \multicolumn{3}{|l|}{ Seasonal flu vaccination can protect me from seasonal flu } \\
\hline Agreement & $14.3(4.1-24.5)$ & .006 \\
\hline \multicolumn{3}{|l|}{$\begin{array}{l}\text { If I get a seasonal flu vaccination, people around me will be bet- } \\
\text { ter protected from seasonal flu }\end{array}$} \\
\hline Agreement & $9.3(0.5-18.0)$ & .038 \\
\hline \multicolumn{3}{|l|}{ Seasonal flu vaccination is safe } \\
\hline Agreement & $17.0(6.2-27.9)$ & .002 \\
\hline \multicolumn{3}{|l|}{$\begin{array}{l}\text { I know everything I need to know to make a good decision } \\
\text { about getting vaccinated for seasonal flu }\end{array}$} \\
\hline Agreement & $6.0(-7.2$ to 19.2$)$ & .373 \\
\hline
\end{tabular}

NOTE. CI, confidence interval.

a Average partial effects are computed based on estimates from multivariable probit models. All estimates were weighted to reflect selected demographic characteristics of US HCP as obtained from the Current Population Survey. ${ }^{32}$

b Other work settings included schools, health departments, mental health facilities, and pharmacies.

c Other occupations included chaplain, clinical counselor, psychologist, psychotherapist, caregiver for adults with developmental disabilities, and veterinarian. 
requirements were not perceived to entail penalties for noncompliance. These results demonstrate that it may be possible to implement influenza vaccination requirements that have the support of a majority of affected staff.

Our results highlight a positive association between the perceived safety of influenza vaccination and higher levels of staff support for influenza vaccination requirements. However, only $37.2 \%$ of those not supporting requirements reported concern about vaccination safety. Thus, other factors likely contribute to lack of support and would need to be addressed to reach high levels of support. Many HCP do not believe that their own vaccination status is a critical factor in protecting themselves, much less their contacts, from influenza. These findings suggest that increased educational outreach regarding the effectiveness of influenza vaccination and heightened awareness of influenza vaccination as a patient safety issue could further increase support for influenza vaccination requirements among affected $\mathrm{HCP}$.

To our knowledge, our study is the first effort to assess the level of support for influenza vaccination requirements in a diverse and representative population of US HCP that covers multiple work settings throughout the nation. However, although our population-based approach was designed to yield a nationally representative sample of US HCP, uncertainty regarding the generalizability of our findings remains. First, we cannot be sure that the panel included a representative sample of US physicians. We do not know whether our initial screening of $\mathrm{KN}$ panelists on the basis of occupation and work setting captured all eligible $\mathrm{HCP}$ in the $\mathrm{KN}$ panel. Our initial sample selection procedure may have had low sensitivity for identifying HCP and could have resulted in a biased sample. Assessing the extent of this potential bias is not possible because of the lack of a well-established benchmark that could be used for comparing our sample with the national population of HCP. Second, all respondents were current members of the $\mathrm{KN}$ panel, which may bias our findings if panel participation was systematically related to the measures used in our analyses. Third, most survey respondents had already completed similar surveys as part of our tracking study throughout the 2009-2010 influenza pandemic, such that potential survey-specific "learning effects" or selective attrition may represent an additional source of bias.

Beyond these potential selection issues, our study does not allow us to establish causality in the relationship between existing vaccination requirements and HCP support for such requirements. Specifically, we cannot evaluate whether existing vaccination requirements were able to generate staff support during their implementation phase or whether such programs were simply implemented in environments that had higher levels of support for mandatory vaccination of $\mathrm{HCP}$ in the first place. Also, our study did not define or collect comprehensive information about the specific nature of the penalties that HCP may face for being out of compliance with vaccination requirements. As such, our findings provide lim- ited guidance for policy makers and medical care managers striving to design and implement influenza vaccination programs that jointly maximize uptake while maintaining employee support. Because relatively few HCP are currently covered by vaccination requirements, our population-based approach did not generate sufficiently large sample sizes for studying more specific aspects of program design and implementation. Additional quantitative and qualitative research studying the relationship between program design, acceptance, and effectiveness conducted at the institutional level could fill this gap more effectively. Finally, our study was conducted at the end of the 2009-2010 influenza $A(H 1 N 1)$ pandemic, during which there may have been heightened interest and concern about influenza among HCP.

Consistent with institution-specific case studies and testimonials, ${ }^{16,17}$ our data suggest that implementing vaccination requirements for HCP may not necessarily generate resistance among affected staff. Vaccination requirements for HCP may help increase vaccination levels in medical care settings over a very short time horizon and are supported by the majority of HCP. Although our data indicated that a sizable minority of HCP still reject influenza vaccination requirements, additional communication of HCP vaccination as a patient safety issue and reassurance of HCP with regard to influenza vaccination safety may potentially increase the level of support for influenza vaccination requirements.

\section{ACKNOWLEDGMENTS}

We are grateful for helpful programming support from Rick Li of Knowledge Networks.

Financial support. Centers for Disease Control and Prevention.

Potential conflicts of interest. All authors report no conflicts of interest relevant to this article. All authors submitted the ICMJE Form for Disclosure of Potential Conflicts of Interest, and the conflicts that the editors consider relevant to this article are disclosed here.

Address correspondence to Jürgen Maurer, PhD, Institute of Health Economics and Management, Route de Chavannes 31, 1015 Lausanne, Switzerland (jurgen.maurer@unil.ch).

The views expressed here are those of the authors alone and do not represent those of the RAND Corporation, the University of Lausanne, or the Centers for Disease Control and Prevention.

\section{REFERENCES}

1. Thompson WW, Shay DK, Weintraub E, et al. Mortality associated with influenza and respiratory syncytial virus in the United States. JAMA 2003;289(2):179-186.

2. Thompson WW, Shay DK, Weintraub E, et al. Influenzaassociated hospitalizations in the United States. JAMA 2004; 292(11):1333-1340.

3. Thompson MG, Shay DK, Zhou $\mathrm{H}$, et al. Estimates of death associated with seasonal influenza-United States 1976-2007. MMWR Morb Mortal Wkly Rep 2010;59(33):1057-1062.

4. Fiore AE, Uyeki T, Broder $K$, et al. Prevention and control of influenza with vaccines: recommendations of the Advisory 
Committee on Immunization Practices (ACIP), 2010. MMWR Recomm Rep 2010;59(RR-8):1-62.

5. Hayward AC, Harling R, Wetten $S$, et al. Effectiveness of an influenza vaccine programme for care home staff to prevent death, morbidity, and health service use among residents: cluster randomised controlled trial. BMJ 2006;333(7581):1241.

6. Lemaitre $M$, Meret $T$, Rothan-Tondeur $M$, et al. Effect of influenza vaccination of nursing home staff on mortality of residents: a cluster-randomized trial. J Am Geriatr Soc 2009;57(9): 1580-1586.

7. Carman WF, Elder AG, Wallace LA, et al. Effects of influenza vaccination of health-care workers on mortality of elderly people in long-term care: a randomised controlled trial. Lancet 2000; 355:93-97.

8. Salgado CD, Farr BM, Hall KK, Hayden FG. Influenza in acute hospital settings. Lancet Infect Dis 2002;2(3):145-155.

9. Sartor C, Zandotti C, Romain F, et al. Disruption of services in an internal medicine unit due to a nosocomial influenza outbreak. Infect Control Hosp Epidemiol 2002;23(10):615-619.

10. Harris KM, Maurer J, Black CL, et al. Interim results: influenza A (H1N1) 2009 monovalent and seasonal influenza vaccination coverage among health-care personnel-United States, August 2009-January 2010. MMWR Morb Mortal Wkly Rep 2010; 59(12):357-362.

11. American Academy of Pediatrics. Policy statementrecommendation for mandatory influenza immunization of all health care personnel. Pediatrics 126(4):809-815.

12. Infectious Diseases Society of America (IDSA). IDSA policy on mandatory immunization of health care workers against seasonal and pandemic influenza. http://www.idsociety.org/ redirector.aspx?id =15413. Accessed October 1, 2010.

13. National Patient Safety Foundation. National Patient Safety Foundation supports mandatory flu vaccinations for healthcare workers. http://www.npsf.org/pr/pressrel/2009-11-18.php. Accessed October 1, 2010.

14. Society for Healthcare Epidemiology of America (SHEA). Revised SHEA position paper: influenza vaccination of healthcare personnel. Infect Control Hosp Epidemiol 2010;31:987-995.

15. Association for Professionals in Infection Control and Epidemiology. APIC calls for mandatory annual flu immunization of healthcare workers. http://www.apic.org/AM/Template.cfm ?Section = Featured_News_and_Events\&CONTENTID $=17428$ \&TEMPLATE $=/ \mathrm{CM} /$ ContentDisplay.cfm. Accessed March 7, 2011.

16. Immunization Action Coalition. Institutional mandates. http:// www.immunize.org/honor-roll/. Accessed October 1, 2010.

17. National Influenza Vaccine Summit. Prevent influenza now! http://www.influenzasummit.org/profs_workers.asp. Accessed September 4, 2010.

18. Rakita RM, Hagar BA, Crome $\mathrm{P}$, et al. Mandatory influenza vaccination of healthcare workers: a 5-year study. Infect Control Hosp Epidemiol 2010;31(9):881-888.
19. Babcock HM, Gemeinhart N, Jones M, et al. Mandatory influenza vaccination of health care workers: translating policy to practice. Clin Infect Dis 2010;50:459-464.

20. Poland GA, Tosh P, Jacobson R. Requiring influenza vaccination for health care workers: seven truths we must accept. Vaccine 2005;23:2251-2255.

21. Talbot TR. Improving rates of influenza vaccination among healthcare workers: educate; motivate; mandate? Infect Control Hosp Epidemiol 2008;29(2):107-110.

22. Sullivan PL. Influenza vaccination in healthcare workers: should it be mandatory? Online J Issues Nurs 2009;15(1). http://www .nursingworld.org/MainMenuCategories/ANAMarketplace/ ANAPeriodicals/OJIN/TableofContents/Vol152010/ NolJan2010/Articles-Previous-Topic/Mandatory-InfluenzaVaccination-in-Healthcare-Workers.aspx. Accessed October 1, 2010.

23. van Delden JJ, Ashcroft R, Dawson A, et al. The ethics of mandatory vaccination against influenza for health care workers. Vaccine 2008;26(44):5562-5566.

24. Isaacs D, Leask J. Should influenza immunisation be mandatory for healthcare workers? no. BMJ 2008;337:a2140.

25. Helms CM, Polgreen PM, Should influenza immunisation be mandatory for healthcare workers? yes. BMJ 2008;337:a2142.

26. Anikeeva $O$, Braunack-Mayer A, Rogers W. Requiring influenza vaccination for health care workers. Am J Public Health 2009; 99:24-29.

27. Steward AM. Mandatory vaccination of healthcare workers. $N$ Engl J Med 2009;361:2015-2017.

28. The New York Times. Judge halts mandatory flu vaccines for health care workers. October 16, 2009. http://cityroom.blogs .nytimes.com/2009/10/16/judge-halts-mandatory-flu-vaccinesfor-health-care-workers/. Accessed March 7, 2011.

29. Knowledge Networks. List of journals publishing articles based on survey data collected by Knowledge Networks. http://www .knowledgenetworks.com/ganp/docs/KN-Journals-List-3-10.pdf. Accessed December 8, 2010.

30. Fiore AE, Shay DK, Broder $\mathrm{K}$, et al. Prevention and control of seasonal influenza with vaccines: recommendations of the Advisory Committee on Immunization Practices (ACIP), 2009. MMWR Recomm Rep 2009;58(RR-8):1-52.

31. Singleton J, Santibanez TA, Lu PJ, et al. Interim results: influenza A (H1N1) 2009 monovalent vaccination coverage-United States, October-December 2009. MMWR Morb Mortal Wkly Rep 2010;59:1-5.

32. Knowledge Networks. Overview of KnowledgePanel statistical weighting protocol. http://www.knowledgenetworks.com/ganp/ docs/KN-Weighting-Synopsis.pdf. Accessed October 1, 2010.

33. Douville LE, Myers A, Jackson MA, Lantos, JD. Health care workers knowledge, attitudes and beliefs regarding mandatory influenza vaccination. Arch Pediatr Adolesc Med 2010;164(1): 33-37. 